\title{
ANALISIS LEARNING TRAJECTORY SISWA KELAS VII SMP DALAM MEMECAHKAN MASALAH PECAHAN BERDASARKAN PERBEDAAN KEMAMPUAN MATEMATIKA
}

\author{
Tria Bitara ${ }^{1}$, Muh. Rizal ${ }^{2}$ \\ triabitara0703@gmail.com ${ }^{1}$, rizaltberu97@yahoo.com² \\ Pendidikan Matematika FKIP UNTAD ${ }^{1}$, Pendidikan Matematika FKIP UNTAD ${ }^{2}$
}

\begin{abstract}
Abstrak: Penelitian ini bertujuan untuk memperoleh deskripsi tentang learning trajectory siswa dalam memecahkan masalah pecahan berdasarkan perbedaan kemampuan matematika. Subjek terdiri dari seorang siswa perempuan yang berkemampuan matematika tinggi (S1) dan seorang siswa perempuan yang berkemampuan matematika rendah (S2). Data learning trajectory diperoleh melalui tes pemecahan masalah dan wawancara yang dianalisis secara kualitatif, yakni menelaah, mereduksi, mengelompokkan, mengkategorisasi, melakukan pengkodean, serta melakukan pemeriksaan data. Pada tahap memahami masalah, S1 dan S2 mula-mula mengidentifikasi satu per satu informasi yang diketahui, kemudian mengidentifikasi hal yang ditanyakan, hingga akhirnya menyatakan bahwa informasi yang tersedia telah cukup agar masalah dapat diselesaikan. Pada tahap menyusun rencana, S1 dan S2 memanfaatkan seluruh informasi yang tersedia, tetapi perencanaan S1 lebih ringkas dibandingkan perencanaan S2 yang bersifat berbelit-belit. Pada tahap melaksanakan rencana, S1 dan S2 menyelesaiakan masalah sesuai dengan perencanaan yang telah disusun, tetapi penyelesaian $\mathrm{S} 1$ lebih ringkas dibandingkan S2. Pada tahap memeriksa kembali, S1 menggunakan alternatif pemeriksaan yang berbeda dari penyelesaian yang telah dilakukannya, sedangkan S2 menelusuri kembali perhitungan yang telah dilakukannya. Perbedaan keduanya di setiap tahapan pemecahan masalah menunjukkan bahwa learning trajectory siswa perempuan yang berkemampuan matematika tinggi lebih pendek dari siswa perempuan yang berkemampuan matematika rendah.
\end{abstract}

Kata kunci: Learning Trajectory, Masalah, Pemecahan Masalah, Perbedaan Kemampuan Matematika

Indonesia merupakan negara yang menjadikan pendidikan sebagai usaha untuk mencerdaskan kehidupan bangsa. Usaha tersebut diwujudkan melalui reformasi pendidikan yang tidak hanya terfokus pada perbaikan sarana dan prasarana pendidikan, melainkan juga pada perbaikan strategi pembelajaran, yakni dengan mengedepankan pembelajaran yang berorientasi pada siswa. Pembelajaran yang berorientasi pada siswa menuntut siswa untuk mampu menemukan dan mengkonstruksi pengetahuan yang mereka miliki yang kemudian berdampak pada pentingnya pengetahuan guru tentang proses berpikir siswa yang mencakup learning trajectory yang siswa miliki.

Nurdin (2011) mendefinisikan learning trajectory sebagai suatu rangkaian aktivitas yang secara aktual dilalui siswa dalam memecahkan suatu masalah atau memahami suatu konsep. Rangkaian aktivitas yang dimaksudkan adalah sederet aktivitas yang berkaitan dengan proses atau tahapan-tahapan berpikir siswa.

Learning trajectory memberikan gambaran terkait proses berpikir siswa yang berarti jika guru mengetahui learning trajectory siswa, maka guru akan memiliki gambaran tentang proses berpikir siswa yang selanjutnya dapat dijadikan sebagai dasar bagi guru dalam merencanakan pembelajaran. Hal ini sebagaimana dinyatakan oleh Anwar dan Rofiki (2018) bahwa pengetahuan tentang learning trajectory siswa dapat membantu guru dalam merencanakan strategi pembelajaran yang berdasarkan proses berpikir matematis siswa. Senada dengan itu, Clements dan Sarama (2004) mengungkapkan bahwa pengetahuan 
tentang learning trajectory siswa akan membantu guru dalam memfasilitasi pembelajaran yang sesuai dengan perkembangan setiap siswa.

Learning trajectory berkaitan erat dengan proses pemecahan masalah karena melalui pemecahan masalah learning trajectory siswa dapat diketahui. Masalah dalam matematika oleh Charles dan Lester dalam Baroody dan Coslick (1998) dinyatakan sebagai soal matematika yang membutuhkan penyelesaian, tetapi penyelesaian dari soal tersebut bersifat nonrutin. Strategi pemecahan masalah menurut Polya (1973) terdiri dari empat tahapan, yakni memahami masalah, menyusun rencana, melaksanakan rencana, dan memeriksa kembali.

Strategi siswa dalam memecahkan masalah dapat berbeda, tergantung dari perbedaan kemampuan matematika mereka. Syamsudin, Awuy, dan Sukayasa (2019) menyatakan bahwa dalam menyelesaikan masalah operasi pecahan bentuk aljabar, siswa berkemampuan matematika tinggi, sedang, dan rendah memiliki pemahaman yang berbedabeda. Perbedaan tersebut mengindikasikan adanya perbedaan learning trajectory pada siswa yang memiliki perbedaan kemampuan matematika dalam memecahkan masalah pecahan. Oleh karenanya, peneliti melakukan penelitian terkait learning trajectory siswa kelas VII Sekolah Menengah Pertama (SMP) dalam memecahkan masalah pecahan.

Pecahan merupakan satu dari topik-topik pembelajaran yang diajarkan mulai dari jenjang pendidikan dasar hingga pendidikan menengah. Topik pecahan dipilih karena pecahan merupakan dasar yang penting untuk mempelajari matematika lebih lanjut, sebagaimana dinyatakan oleh Fennel (2007) dalam tulisannya di situs NCTM, yakni "Proficiency with fraction is an important foundation for learning more advanced mathematics". Oleh karena pentingnya penguasaan materi ini bagi siswa, maka pengetahuan guru terkait learning trajectory siswa pada topik ini pun menjadi penting. Learning trajectory siswa dalam memecahkan masalah pecahan akan memberikan suatu kerangka kerja bagi guru untuk mengembangkan pengetahuan tentang berpikir dan belajar siswa yang selanjutnya dapat digunakan dalam merencanakan pembelajaran pada topik ini. Sebaliknya, ketidaktahuan guru tentang learning trajectory siswa dalam memecahkan masalah pecahan akan menyebabkan ketidaktahuan guru tentang proses berpikir siswa yang mungkin saja panjang dan berbelit-belit, sehingga dikhawatirkan kedepannya siswa tidak mampu memecahkan masalah pecahan secara efektif.

\section{METODE}

Penelitian ini tergolong dalam jenis penelitian deskriptif-kualitatif dan dilakukan di SMPN Model Terpadu Madani Palu pada semester gasal tahun ajaran 2019/2020. Subjek penelitian ini adalah seorang siswa perempuan yang berkemampuan matematika tinggi (S1) dan seorang siswa perempuan yang berkemampuan matematika rendah (S2) yang dijaring melalui tes kemampuan matematika. Pengelompokkan siswa berdasarkan kemampuan matematikanya mengacu pada pendapat Ratumanan dan Laurens dalam Rizal (2011), yakni tinggi apabila nilai $\geq 75$, sedang apabila $60 \leq$ nilai $<75$, dan rendah apabila nilai $<60$.

Data learning trajectory subjek dalam memecahkan masalah pecahan diperoleh melalui tes pemecahan masalah dan wawancara yang kemudian dianalisis secara kualitatif berdasarkan teknik analisis data menurut Moleong (2018), yakni menelaah seluruh data, mereduksi data, mengelompokkan data, mengkategorisasi, melakukan pengkodean, serta melakukan pemeriksaan data dengan triangulasi waktu. 
102 AKSIOMA, Volume 10 Nomor 2, September 2021

\section{HASIL DAN PEMBAHASAN}

Uji kredibilitas terhadap data kedua subjek dengan triangulasi waktu menunjukkan bahwa data keduanya dalam memecahkan Masalah 1 (M1) dan Masalah 2 (M2) adalah kredibel, sehingga data yang dianalisis dan dibahas hanyalah data kedua subjek dalam memecahkan M1.

\section{S1 dan S2 dalam Memahami Masalah}

Hasil reduksi terhadap data hasil wawancara S1 dalam memahami M1 disajikan dalam Tabel 1 sebagai berikut.

Tabel 1. Hasil Wawancara S1 dalam Memahami M1

\begin{tabular}{clr}
\hline P/S1 & \multicolumn{1}{c}{ Kalimat Wawancara } & \multicolumn{1}{c}{ Kode } \\
Pawancara
\end{tabular}

Hasil reduksi terhadap data hasil wawancara S2 dalam memahami M1 disajikan dalam Tabel 2 sebagai berikut.

Tabel 2. Hasil Wawancara S2 dalam Memahami M1

\begin{tabular}{llr}
\hline P/S2 & \multicolumn{1}{c}{ Kalimat Wawancara } & $\begin{array}{c}\text { Kode } \\
\text { Wawancara }\end{array}$ \\
\hline $\mathrm{P}:$ & Apa yang Adik pahami dari soal ini? & PM1-007 \\
S2: & $\begin{array}{l}\text { Pak Ahmad akan membagikan tanah kavelingannya untuk ketiga anaknya dengan } \\
\text { ketentuan anak yang lebih tua harus dapat kavelingan yang lebih luas. }\end{array}$ \\
$\mathrm{P}:$ & $\begin{array}{l}\text { Maksudnya itu bagaimana? } \\
\text { S2: }\end{array}$ & Hmm, anaknya Pak Ahmad dari yang paling tua itu Hendra, kedua Ahsan, terakhir Rian. \\
& Hendra punya tanah lebih luas dari Ahsan, Ahsan punya lebih luas dari Rian. & S2M1-010
\end{tabular}


$\mathrm{P}:$ Oke.

PM1-011

S2: Luas tanah kavelingan keseluruhan yaitu $1.200 \mathrm{~m}^{2}$, dengan luas masing-masing yaitu:

Kavelingan A luasnya 22\% dari luas keseluruhan, Kavelingan B luasnya $\frac{11}{25}$ bagian dari luas keseluruhan, Kavelingan $\mathrm{C}$ luasnya 0,34 bagian dari luas keseluruhan.

$\mathrm{P}$ : Iya.

PM1-013

S2 : Hendra akan membagikan setengah dari luas miliknya untuk Ahsan dan Rian sama luas.

S2M1-014

$\mathrm{P}$ : Maksudnya?

PM1-015

S2 : Maksudnya kavelingannya Hendra itu setengahnya mau dibagi dua untuk diberikan ke

Ahsan dan Rian sama luas.

$\mathrm{P}$ : Sudah ditahu miliknya mereka bertiga kavelingan yang mana saja?

PM1-017

S2 : Hmm, belum Kak.

S2M1-018

PM1-019

$\mathrm{P}$ : Masih ada lagi yang Adik pahami?

S2M1-020

S2: Pertanyaanya itu berapa persentase luas tanah milik mereka masing-masing.

PM1-021

$\mathrm{P}:$ Apa maksudnya?

S2M1-022

berapa persen luas tanahnya Rian.

$\mathrm{P}:$ Terus?

PM1-025

S2: Ya dikerjakan berarti Kak.

S2M1-026

$\mathrm{P}$ : Sudah cukupkah informasi di soal ini untuk dikerjakan?

PM1-027

S2: Iya Kak, sudah.

S2M1-028

Hasil penelaahan terhadap data tersebut menunjukan bahwa dalam memahami M1, S1 dan S2 mula-mula mengidentifikasi satu per satu informasi yang tersedia. Setelah itu, keduanya mengidentifikasi hal yang ditanyakan atau diinginkan dari M1. Untuk memperoleh jawaban dari hal yang ditanyakan, maka keduanya mengaitkan antara informasi yang diketahui dengan hal yang ditanyakan, hingga akhirnya keduanya menyatakan bahwa informasi yang tersedia telah cukup untuk menyelesaikan M1.

\section{S1 dan S2 dalam Menyusun Rencana}

Hasil reduksi terhadap data hasil wawancara $\mathrm{S} 1$ dalam menyusun rencana penyelesaian M1 disajikan dalam Tabel 3 sebagai berikut.

Tabel 3. Hasil Wawancara S1 dalam Menyusun Rencana Penyelesaian M1

\begin{tabular}{|c|c|c|}
\hline$P / S 1$ & Kalimat Wawancara & $\begin{array}{c}\text { Kode } \\
\text { Wawancara }\end{array}$ \\
\hline $\mathrm{P}:$ & Oke, apa yang akan Adik lakukan untuk menyelesaikan soal ini? & PM1-029 \\
\hline S1 : & Dicari dulu kavelingan milik Hendra, Ahsan, dan Rian. & S1M1-030 \\
\hline $\mathrm{P}:$ & Caranya? & PM1-031 \\
\hline S1: & Diurutkan luas tiga kavelingan supaya ditahu mana yang luas pertama, kedua, dan ketiga. & S1M1-032 \\
\hline $\mathrm{P}:$ & Caranya mengurutkan bagaimana? & PM1-033 \\
\hline S1: & Dicari dulu luas A, B, dan C masing-masing dikali $1.200 \mathrm{~m}^{2}$. & S1M1-034 \\
\hline $\mathrm{P}:$ & Kenapa? & PM1-035 \\
\hline S1: & $\begin{array}{l}\text { Supaya ditahu luasnya masing-masing supaya bisa diurutkan. Nanti yang paling luas } \\
\text { untuk Hendra, yang kedua untuk Ahsan, yang ketiga untuk Rian. }\end{array}$ & S1M1-036 \\
\hline $\mathrm{P}:$ & Setelah itu? & PM1-037 \\
\hline S1: & $\begin{array}{l}\text { Hendra punya dibagi dua supaya dapat setengah. Setengahnya itu dibagi dua lagi untuk } \\
\text { Ahsan dan Rian. Berarti punyanya Hendra berkurang, punyanya Ahsan bertambah, Rian } \\
\text { juga bertambah. }\end{array}$ & S1M1-038 \\
\hline $\mathrm{P}:$ & Setelah itu? & PM1-039 \\
\hline S1: & Dipersentasekan luasnya Kak. & S1M1-040 \\
\hline $\mathrm{P}:$ & Terus? & PM1-041 \\
\hline S1: & Didapat sudah jawabannya Kak. & S1M1-042 \\
\hline
\end{tabular}


Hasil reduksi terhadap data hasil wawancara S2 dalam menyusun rencana penyelesaian M1 disajikan dalam Tabel 4 sebagai berikut.

Tabel 4. Hasil Wawancara S2 dalam Menyusun Rencana Penyelesaian M1

\begin{tabular}{|c|c|c|}
\hline$P / S 2$ & Kalimat Wawancara & $\begin{array}{c}\text { Kode } \\
\text { Wawancara }\end{array}$ \\
\hline $\mathrm{P}:$ & Apa yang akan Adik lakukan untuk menyelesaikan soal ini? & PM1-029 \\
\hline S2: & Dicari kavelingannya Hendra, Ahsan, dan Rian. & S2M1-030 \\
\hline $\mathrm{P}:$ & Caranya? & PM1-031 \\
\hline S2: & Kavelingan A, B, dan C diurutkan mana yang paling luas. & S2M1-032 \\
\hline $\mathrm{P}:$ & Caranya mengurutkan bagaimana? & PM1-033 \\
\hline S2: & Dijadikan persen semua. & S2M1-034 \\
\hline $\mathrm{P}:$ & Setelah itu? & PM1-035 \\
\hline S2: & Nanti didapat kavelingannya Hendra, Ahsan, dan Rian. & S2M1-036 \\
\hline P : & Terus? & PM1-037 \\
\hline S2: & Dicari luas kavelingan itu semua. & S2M1-038 \\
\hline P : & Maksudnya? & PM1-039 \\
\hline S2: & Dicari luasnya Kavelingan A, B, dan C berapa. & S2M1-040 \\
\hline P : & Caranya? & PM1-041 \\
\hline S2: & Persennya dikali luas seluruh tanah. & S2M1-042 \\
\hline $\mathrm{P}:$ & Terus? & PM1-043 \\
\hline S2: & $\begin{array}{l}\text { Hendra punya dibagi dua, nanti dapat setengah. Setengah itu dibagi dua lagi untuk Ahsan } \\
\text { dan Rian. }\end{array}$ & S2M1-044 \\
\hline $\mathrm{P}:$ & Setelah itu? & PM1-045 \\
\hline S2: & $\begin{array}{l}\text { Hendra punya sisa setengah, Ahsan punya ditambah yang dari Hendra, Rian punya juga } \\
\text { ditambah yang dari Hendra. }\end{array}$ & S2M1-046 \\
\hline P : & Setelah itu? & PM1-047 \\
\hline S2 : & Diubah ke persen Kak. & S2M1-048 \\
\hline $\mathrm{P}:$ & Kalau sudah diubah ke persen? & PM1-049 \\
\hline S2: & Sudah, didapat jawabannya nanti. & S2M1-050 \\
\hline
\end{tabular}

Hasil penelaahan terhadap data tersebut menunjukkan bahwa dalam menyusun rencana penyelesaian $\mathrm{M} 1, \mathrm{~S} 1$ dan S2 memanfaatkan seluruh informasi yang tersedia tanpa terkecuali. S1 mula-mula merencanakan penggunaan operasi perkalian pecahan dengan luas keseluruhan tanah untuk kemudian diurutkan, kemudian merencanakan penggunaan berbagai operasi hitung seperti pembagian, pengurangan, dan penjumlahan bilangan bulat, hingga akhirnya merencanakan penggunaan pengubahan bilangan bulat menjadi persen, sedangkan S2 mula-mula merencanakan penggunaan pengubahan bentuk pecahan menjadi persen untuk kemudian diurutkan, kemudian merencanakan penggunaan operasi perkalian pecahan dengan luas keseluruhan tanah, kemudian merencanakan penggunaan berbagai operasi hitung seperti pembagian, pengurangan, dan penjumlahan bilangan bulat, hingga akhirnya merencanakan penggunaan pengubahan bilangan bulat menjadi persen.

Perbedaan pada aktivitas berpikir yang dilalui S1 dan S2 dalam menyusun rencana penyelesaian M1 menunjukkan bahwa S1 yang merupakan siswa berkemampuan matematika tinggi memiliki perencanaan yang lebih pendek dibandingkan S2 yang merupakan siswa berkemampuan matematika rendah.

\section{S1 dan S2 dalam Melaksanakan Rencana}

Hasil pekerjaan S1 dan S2 dalam melaksanakan rencana peyelesaian M1 berturutturut disajikan dalam Gambar 1 dan Gambar 2 sebagai berikut. 


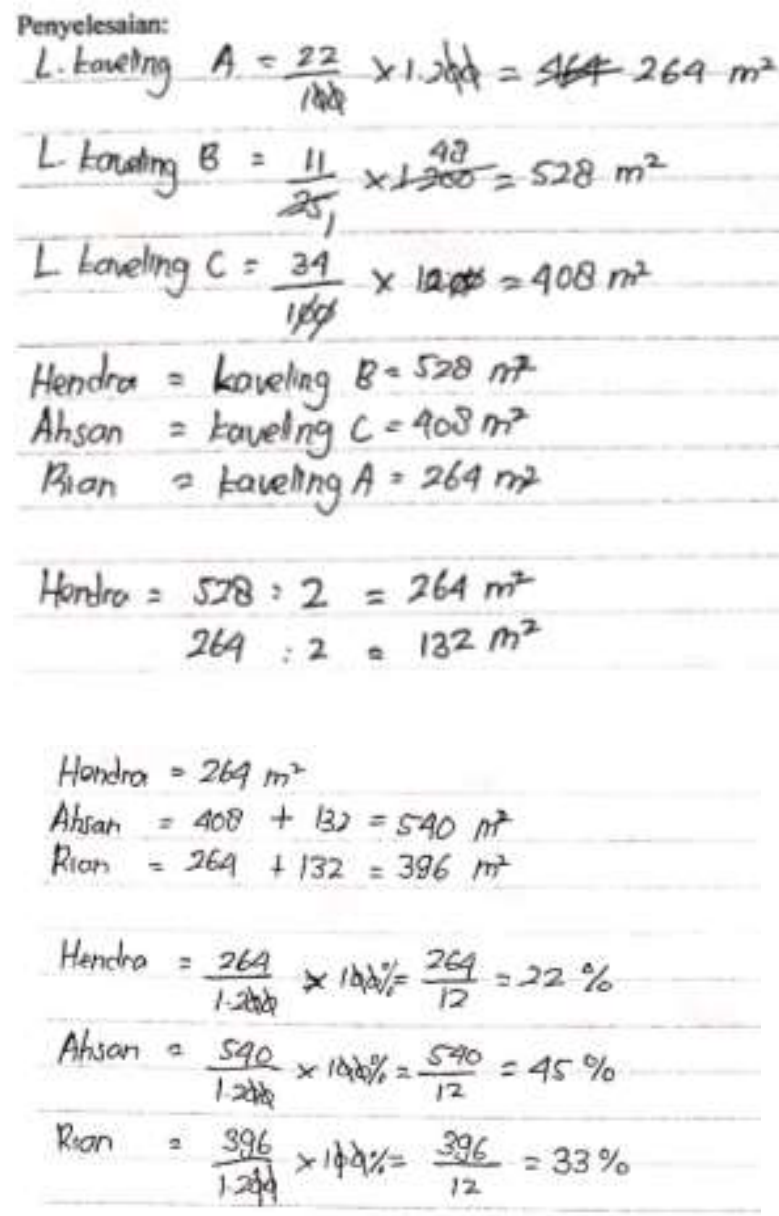

Gambar 1. Hasil Pekerjaan S1 pada M1

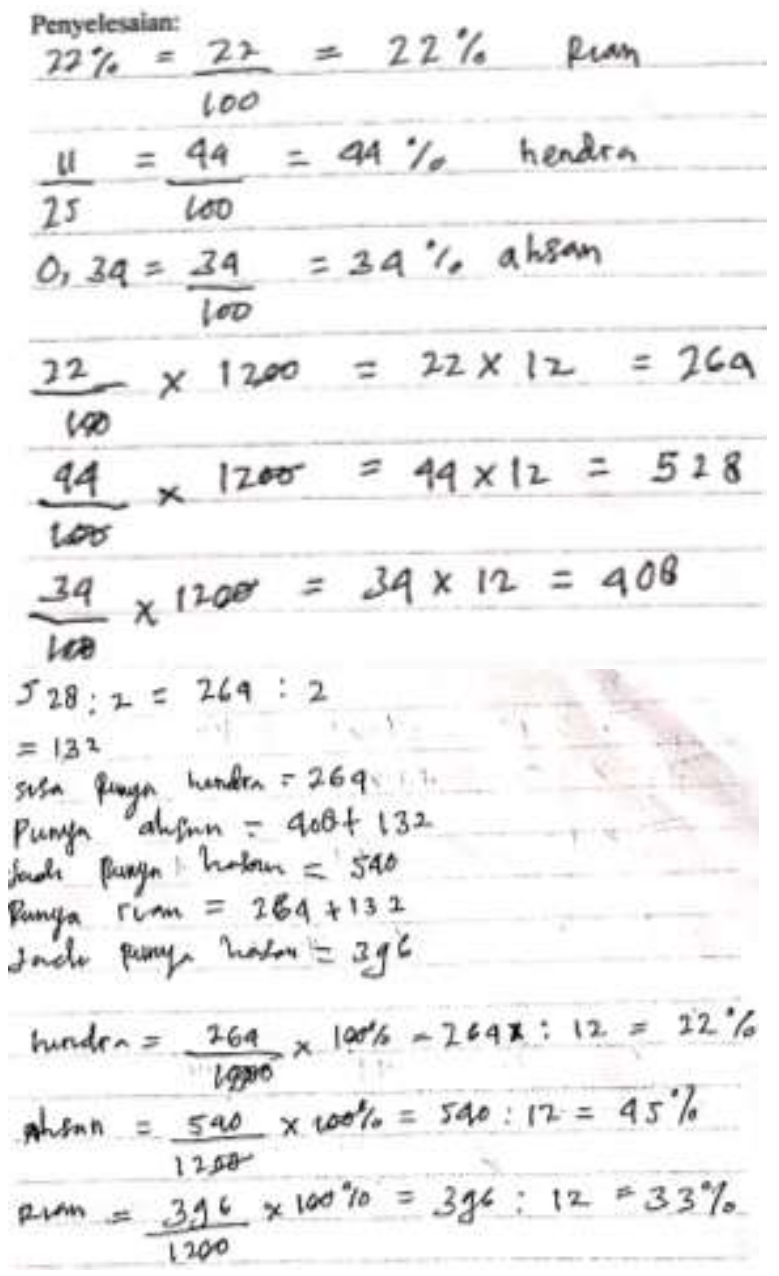

Gambar 2. Hasil Pekerjaan S2 pada M1

Hasil reduksi terhadap data hasil wawancara S1 dalam melaksanakan rencana penyelesaian M1 disajikan dalam Tabel 5 sebagai berikut.

Tabel 5. Hasil Wawancara S1 dalam Melaksanakan Rencana Penyelesaian M1

\begin{tabular}{|c|c|}
\hline$P / S 1$ & Kalimat Wawancara \\
\hline & Oke, coba kerjakan. \\
\hline S1: & $\begin{array}{l}\text { (Sambil menuliskan penyelesaian) Luas Kaveling A adalah } 22 \%=\frac{22}{100} \times 1200=22 \times \\
12=464 \text {, eh } 264 \mathrm{~m}^{2} . \text { Luas Kaveling B adalah } \frac{11}{25} \times 1200=11 \times 48=528 \mathrm{~m}^{2} . \text { Luas } \\
\text { Kaveling C adalah } 0,34=\frac{34}{100} \times 1200=34 \times 12=408 \mathrm{~m}^{2} .\end{array}$ \\
\hline $\mathrm{P}:$ & Setelah itu? \\
\hline S1 : & $\begin{array}{l}\text { (Sambil menuliskan penyelesaian) Hendra punya Kaveling } \mathrm{B}=528 \mathrm{~m}^{2} \text {, Ahsan punya } \\
\text { Kaveling } \mathrm{C}=408 \mathrm{~m}^{2} \text {, Rian punya Kaveling } \mathrm{A}=264 \mathrm{~m}^{2} .\end{array}$ \\
\hline $\mathrm{P}:$ & Terus? \\
\hline S1: & $\begin{array}{l}\text { (Sambil menuliskan penyelesaian) Hendra punya dibagi dua, berarti } 528 \div 2=264 \mathrm{~m}^{2} \text {, } \\
\text { dibagi dua lagi } 264 \div 2=132 \mathrm{~m}^{2} \text {. Berarti Hendra punya sisa } 264 \mathrm{~m}^{2} \text { karena berkurang } \\
\text { setengah, Ahsan punya } 408+132=540 \mathrm{~m}^{2} \text { karena ditambah dari Hendra punya, kalau } \\
\text { Rian } 264+132=396 \mathrm{~m}^{2} \text { karena ditambah juga dari Hendra punya. }\end{array}$ \\
\hline $\mathrm{P}:$ & Setelah itu? \\
\hline S1: & (Sambil menuliskan penyelesaian) Hendra punya $\frac{264}{1200} \times 100 \%=\frac{264}{12}=22 \%$. Ahsan \\
\hline
\end{tabular}

PM1-045

S1M1-046

PM1-047

S1M1-048

PM1-049

S1M1-050 
punya $\frac{540}{1200} \times 100 \%=\frac{540}{12}=45 \%$. Rian punya $\frac{396}{1200} \times 100 \%=\frac{396}{12}=33 \%$.

$\mathrm{P}$ : Jadi, persentase luas tanah milik mereka masing-masing berapa?

PM1-051

S1 : $\quad$ Hendra 22\%, Ahsan 45\%, Rian 33\%.

S1M1-052

Hasil reduksi terhadap data hasil wawancara S2 dalam melaksanakan rencana penyelesaian M1 disajikan dalam Tabel 6 sebagai berikut.

Tabel 6. Hasil Wawancara S2 dalam Melaksanakan Rencana Penyelesaian M1

\begin{tabular}{|c|c|c|}
\hline$P / S 2$ & Kalimat Wawancara & $\begin{array}{c}\text { Kode } \\
\text { Wawancara }\end{array}$ \\
\hline $\mathrm{P}:$ & Oke, coba kerjakan Dik. & PM1-051 \\
\hline S2: & $\begin{array}{l}\text { (Sambil menuliskan penyelesaian) A luasnya } 22 \%=\frac{22}{100}=22 \% \text {. B luasnya } \frac{11}{25}=\frac{44}{100}= \\
44 \% \text {. C luasnya } 0,34=\frac{34}{100}=34 \% .\end{array}$ & S2M1-052 \\
\hline $\mathrm{P}:$ & Kenapa jadi begitu Dik? & PM1-053 \\
\hline S2 : & Yang mana Kak? & S2M1-054 \\
\hline $\mathrm{P}:$ & Ini semua (sambil menunjuk hasil pekerjaan S4). & PM1-055 \\
\hline S2 : & $\begin{array}{l}\text { Ini } 22 \%=\frac{22}{100} \text { karena persen itu perseratus. Ini } \frac{11}{25}=\frac{44}{100} \text { karena dikali } 4 \text { pembilang dan } \\
\text { penyebutnya, karena perseratus makanya jadi } 44 \% \text {. Kalau yang } 0,34=\frac{34}{100} \text { karena ada } \\
\text { dua angka di belakang koma, karena perseratus juga makanya jadi } 34 \% .\end{array}$ & S2M1-056 \\
\hline $\mathrm{P}:$ & & PM1-057 \\
\hline S2 : & $\begin{array}{l}\text { (Sambil menuliskan penyelesaian) Hendra punya yang B, Ahsan punya yang C, Rian } \\
\text { punya yang A. }\end{array}$ & S2M1-058 \\
\hline $\mathrm{P}:$ & 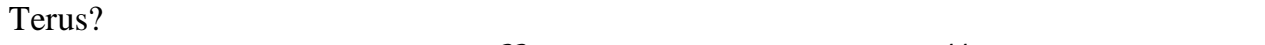 & PM1-059 \\
\hline S2 : & $\begin{array}{l}\text { (Sambil menuliskan penyelesaian) } \frac{22}{100} \times 1200=22 \times 12=264, \frac{44}{100} \times 1200=44 \times \\
12=528, \frac{34}{100} \times 1200=34 \times 12=408 .\end{array}$ & S2M1-060 \\
\hline $\mathrm{P}:$ & Itu luasnya masing-masing dalam $m^{2} ?$ & PM1-061 \\
\hline S2 : & Iya Kak. & S2M1-062 \\
\hline $\mathrm{P}:$ & Setelah itu? & PM1-063 \\
\hline S2: & (Sambil menuliskan penyelesaian) Hendra punya $528 \div 2=264 \div 2=132$ & S2M1-064 \\
\hline $\mathrm{P}:$ & Oke, terus? & PM1-065 \\
\hline S2: & $\begin{array}{l}\text { (Sambil menuliskan penyelesaian) Hendra punya sisa } 264 \text {. Punya Ahsan } 408+132 \text {, jadi } \\
\text { punya Ahsan } 540 \text {. Punya Rian } 264+132 \text {, jadi punya Ahsan, eh maksudnya Rian } 396 \text {. }\end{array}$ & S2M1-066 \\
\hline $\mathrm{P}:$ & Selanjutnya bagaimana? & PM1-067 \\
\hline S2: & $\begin{array}{l}\text { (Sambil menuliskan penyelesaian) Hendra } \frac{264}{1200} \times 100 \%=264 \div 12=22 \% \text {. Ahsan } \\
\frac{540}{1200} \times 100 \%=540 \div 12=45 \% \text {. Rian } \frac{396}{1200} \times 100 \%=396 \div 12=33 \% .\end{array}$ & S2M1-068 \\
\hline $\mathrm{P}:$ & Jadi, persentase luas tanah milik mereka masing-masing berapa? & PM1-069 \\
\hline S2: & Hendra 22\%, Ahsan 45\%, Rian 33\%. & S2M1-070 \\
\hline
\end{tabular}

Hasil penelaahan terhadap data tersebut menunjukkan bahwa rencana penyelesaian yang disusun oleh S1 dan S2 sejalan dengan pelaksanaannya. Hal ini terlihat dari kesamaan rencana yang diungkapkan sebelumnya dengan pelaksanaan yang mereka lakukan. S1 mula-mula mengalikan pecahan dengan luas keseluruhan tanah. Hasil perkalian antara pecahan dengan luas keseluruhan tanah ini menghasilkan luas kavelingan dalam bentuk bilangan bulat, sehingga S1 kemudian melakukan pembagian, pengurangan, dan penjumlahan bilangan bulat. Hal yang diinginkan atau ditanyakan dari M1 adalah persentase, oleh karena itu S1 kemudian harus mengubah lagi bilangan bulat menjadi persen, sedangkan S2 mula-mula mengubah bentuk pecahan menjadi persen untuk kemudian diurutkan, kemudian mengalikan pecahan dengan luas keseluruhan tanah untuk memperoleh luas tanah milik masing-masing anak. Oleh karena luas masing-masing 
kavelingan yang diperoleh dinyatakan dalam bilangan bulat, maka selanjutnya S2 melakukan pembagian, pengurangan, dan penjumlahan bilangan bulat untuk mengetahui luas tanah masing-masing anak setelah Hendra memberikan setengah dari luas tanah miliknya kepada Ahsan dan Rian. Selanjutnya, S2 mengubah bilangan bulat menjadi persen hingga diperoleh persentase luas tanah masing-masing anak karena yang ditanyakan adalah persentasenya.

Perbedaan pada aktivitas berpikir yang dilalui S1 dan S2 dalam melaksanakan rencana penyelesaian M1 menunjukkan bahwa S1 yang merupakan siswa berkemampuan matematika tinggi memiliki perencanaan yang lebih pendek dibandingkan S2 yang merupakan siswa berkemampuan matematika rendah. Penyelesaian yang dilakukan oleh S2 bersifat berbelit-belit karena terdapat satu prosedur yang sebenarnya tidak diperlukan, yakni prosedur pertama ketika S2 mengubah bentuk pecahan menjadi persen untuk kemudian diurutkan agar diperoleh kavelingan milik masing-masing anak. Meski tanpa melalui prosedur ini sebenarnya kavelingan milik masing-masing anak tetap dapat diperoleh melalui prosedur kedua ketika S2 mengalikan pecahan dengan luas keseluruhan tanah.

\section{S1 dan S2 dalam Memeriksa Kembali}

Hasil coret-coretan S1 dalam memeriksa kembali M1 disajikan dalam Gambar 3 sebagai berikut.

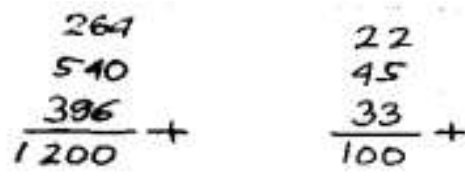

Gambar 3. Hasil Coret-Coretan S1 pada M1

Hasil coret-coretan S2 dalam memeriksa kembali M1 disajikan dalam Gambar 4 sebagai berikut.

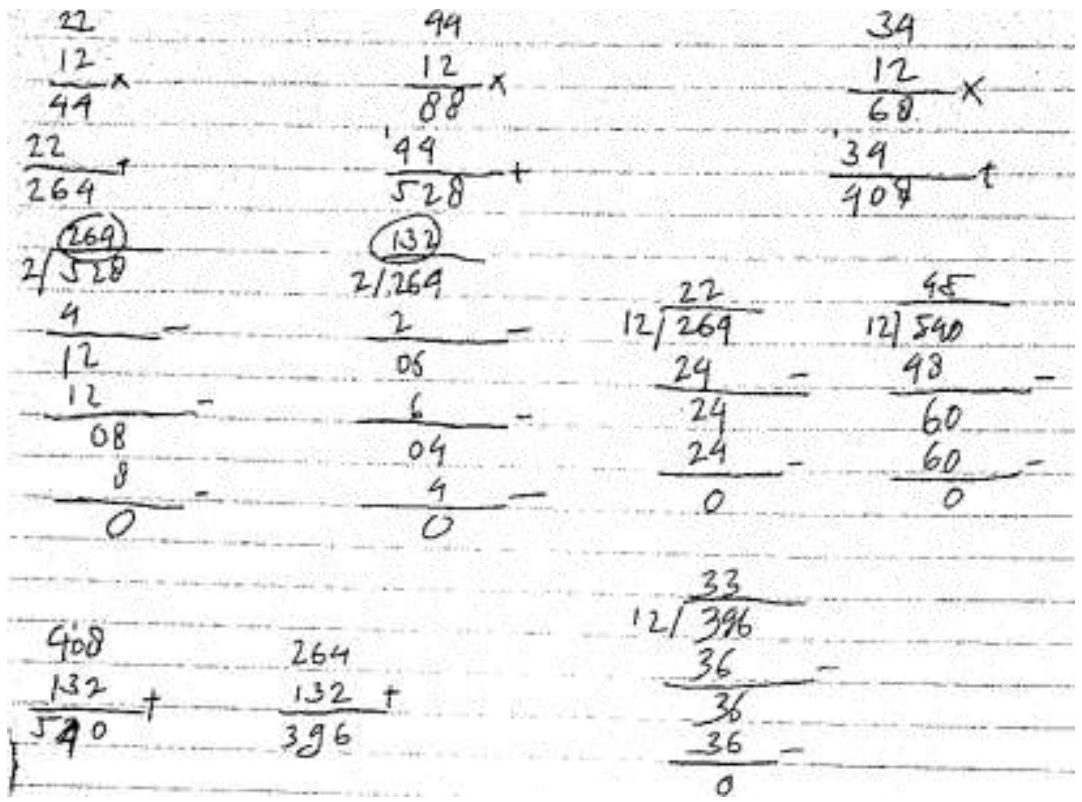

Gambar 4. Hasil Coret-Coretan S2 pada M1 
Hasil reduksi terhadap data hasil wawancara S1 dalam memeriksa kembali M1 disajikan dalam Tabel 7 sebagai berikut.

Tabel 7. Hasil Wawancara S1 dalam Memeriksa Kembali M1

\begin{tabular}{|c|c|c|}
\hline$P / S 1$ & Kalimat Wawancara & $\begin{array}{c}\text { Kode } \\
\text { Wawancara }\end{array}$ \\
\hline & Sudah yakin? & PM1-053 \\
\hline S1: & Tunggu Kak, saya hitung dulu. & S1M1-054 \\
\hline $\mathrm{P}:$ & Apa yang kamu hitung? & PM1-055 \\
\hline S1: & $\begin{array}{l}\text { (Sambil menghitung di kertas coret-coretan) } 264+540+396=1200 \text {, luas tanahnya } \\
\text { Hendra, Ahsan, dengan Rian kalau dijumlah sama dengan luas seluruh kavelingan. }\end{array}$ & S1M1-056 \\
\hline $\mathrm{P}:$ & Jadi sudah benar? & PM1-057 \\
\hline S1: & $\begin{array}{l}\text { (Sambil menghitung di kertas coret-coretan) } 22 \%+45 \%+33 \%=100 \% \text {, ini totalnya } \\
100 \% \text {. }\end{array}$ & S1M1-058 \\
\hline $\mathrm{P}:$ & Jadi, itu sudah jawabannya? & PM1-059 \\
\hline S1: & $\begin{array}{l}\text { Iya Kak, karena hasilnya yang } 1200 \text { itu sama dengan luas seluruh tanah. Persennya juga } \\
\text { kalau dijumlah jadi } 100 \% \text {. }\end{array}$ & S1M1-060 \\
\hline
\end{tabular}

Hasil reduksi terhadap data hasil wawancara S2 dalam memeriksa kembali M1 disajikan dalam Tabel 8 sebagai berikut.

Tabel 8. Hasil Wawancara S2 dalam Memeriksa Kembali M1

\begin{tabular}{llr}
\hline$P / S 2$ & \multicolumn{1}{c}{ Kalimat Wawancara } & Kode \\
\hline $\mathrm{P}:$ & Sudah yakin? & PM1-071 \\
$\mathrm{S} 2:$ & Belum Kak, saya hitung ulang dulu. & S2M1-072 \\
$\mathrm{P}:$ & Silahkan. & $\mathrm{PM} 1-073$ \\
$\mathrm{~S} 2:$ & (Memeriksa perhitungan di kertas coret-coretan) & $\mathrm{S} 2 \mathrm{M} 1-074$ \\
$\mathrm{P}:$ & Sudah yakin? & $\mathrm{PM} 1-075$ \\
$\mathrm{~S} 2:$ & Sudah. & $\mathrm{S} 2 \mathrm{M} 1-076$ \\
$\mathrm{P}:$ & Kenapa kamu yakin? & $\mathrm{PM}-077$ \\
$\mathrm{~S} 2:$ & Karena saya cek benar sudah. & $\mathrm{S} 2 \mathrm{M} 1-078$ \\
$\mathrm{P}:$ & Apa yang kamu cek? & $\mathrm{PM} 1-079$ \\
$\mathrm{~S} 2:$ & Hitunganku di cakaran tadi Kak. & $\mathrm{S} 2 \mathrm{M} 1-080$ \\
\hline
\end{tabular}

Hasil penelaahan terhadap data tersebut menunjukkan bahwa S1 memeriksa dengan cara menjumlahkan luas tanah seluruh anak di kertas coret-coretan yang ternyata jumlahnya adalah $1200 \mathrm{~m}^{2}$. Tidak hanya sampai di situ, S1 melanjutkan pemeriksaan dengan cara menjumlahkan persentase luas tanah seluruh anak di kertas coret-coretan yang ternyata jumlahnya adalah 100\%. Oleh karena jumlah luas seluruh tanah adalah sama dengan informasi yang tertera pada soal dan jumlah persentase luas tanah adalah $100 \%$, maka S1 yakin dengan kebenaran jawabannya, sedangkan S2 memeriksa dengan cara mengecek perhitungan yang telah dilakukan di kertas coret-coretan dan ternyata perhitungan yang telah S2 lakukan benar, sehingga S2 yakin dengan kebenaran jawabannya.

Perbedaan pada aktivitas berpikir yang dilalui S1 dan S2 dalam memeriksa kembali M1 menunjukkan bahwa S1 yang merupakan siswa berkemampuan matematika tinggi mampu berpikir secara logis dengan menyimpulkan jika jumlah luas tanah seluruh anak adalah sama dengan informasi yang diketahui dari soal dan jika jumlah persentase luas tanah seluruh anak adalah 100\%, maka dapat dipastikan jawaban yang diperolehnya benar, sedangkan S2 yang merupakan siswa berkemampuan matematika rendah memilih untuk menelusuri kembali perhitungan yang telah dilakukannya dan karena perhitungannya telah benar, maka dapat dipastikan bahwa jawaban yang diperolehnya bernilai benar. 


\section{Learning Trajectory S1 dan S2 dalam Memecahkan Masalah Pecahan}

Berikut merupakan skema learning trajectory S1 dalam memecahkan M1. Skema disajikan dengan menggunakan simbol-simbol, diantaranya A, B, C, dan D yang secara berturut-turut menunjukkan aktivitas berpikir subjek pada tahap memahami masalah, menyusun rencana, melaksanakan rencana, hingga memeriksa kembali. Digit pertama pada indeks menunjukkan subjek, sedangkan digit kedua pada indeks menunjukkan urutan aktivitas berpikir subjek.

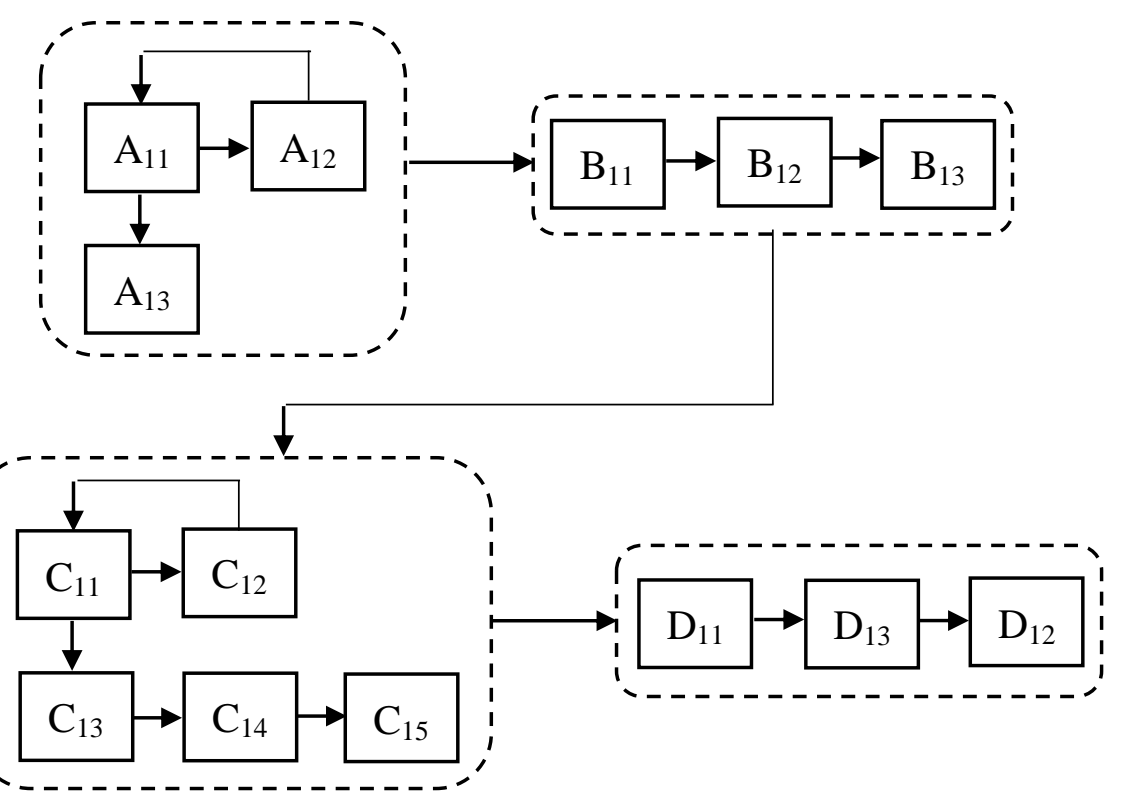

Gambar 5. Skema Learning Trajectory S1

Arti kode yang digunakan pada skema tersebut dirincikan dalam Tabel 9 sebagai berikut.

Tabel 9. Arti Kode Skema Learning Trajectory S1

\begin{tabular}{|c|c|}
\hline Kode & Arti Kode \\
\hline $\mathrm{A}_{11}$ & Mengidentifikasi satu per satu informasi yang diketahui \\
\hline $\mathrm{A}_{12}$ & Mengidentifikasi hal yang ditanyakan \\
\hline $\mathrm{A}_{13}$ & Mengidentifikasi kelengkapan informasi yang dibutuhkan untuk menyelesaikan M1 \\
\hline $\mathrm{B}_{11}$ & $\begin{array}{l}\text { Merencanakan penggunaan operasi perkalian pecahan dengan luas keseluruhan tanah untuk } \\
\text { memperoleh kavelingan milik Hendra, Ahsan, dan Rian }\end{array}$ \\
\hline $\mathrm{B}_{12}$ & $\begin{array}{l}\text { Merencanakan penggunaan operasi hitung seperti pembagian, pengurangan, dan penjumlahan } \\
\text { bilangan bulat untuk memperoleh luas tanah milik mereka masing-masing setelah Hendra } \\
\text { memberikan setengah dari luas kavelingan miliknya kepada Ahsan dan Rian }\end{array}$ \\
\hline $\mathrm{B}_{13}$ & $\begin{array}{l}\text { Merencanakan penggunaan pengubahan bilangan bulat menjadi persen untuk memperoleh } \\
\text { persentase luas tanah milik mereka masing-masing }\end{array}$ \\
\hline $\mathrm{C}_{11}$ & $\begin{array}{l}\text { Mengalikan pecahan dengan luas keseluruhan tanah untuk memperoleh kavelingan milik } \\
\text { Hendra, Ahsan, dan Rian }\end{array}$ \\
\hline $\mathrm{C}_{12}$ & $\begin{array}{l}\text { Melakukan pembagian bilangan bulat untuk memperoleh luas tanah yang ingin diberikan } \\
\text { Hendra kepada Ahsan dan Rian }\end{array}$ \\
\hline $\mathrm{C}_{13}$ & $\begin{array}{l}\text { Melakukan pengurangan bilangan bulat untuk memperoleh luas tanah yang masih dimiliki } \\
\text { Hendra }\end{array}$ \\
\hline $\mathrm{C}_{14}$ & $\begin{array}{l}\text { Melakukan penjumlahan bilangan bulat untuk memperoleh luas tanah yang dimiliki Ahsan dan } \\
\text { Rian setelah ditambah dengan pemberian dari Hendra }\end{array}$ \\
\hline $\mathrm{C}_{15}$ & $\begin{array}{l}\text { Mengubah bilangan bulat menjadi persen untuk memperoleh persentase luas tanah milik } \\
\text { mereka masing-masing }\end{array}$ \\
\hline
\end{tabular}


110 AKSIOMA, Volume 10 Nomor 2, September 2021

$\mathrm{D}_{11} \quad$ Menghitung total luas tanah dari masing-masing anak di kertas coret-coretan

$\mathrm{D}_{12} \quad$ Menghitung total persentase luas tanah dari masing-masing anak di kertas coret-coretan

$\mathrm{D}_{13}$ Meyakini kebenaran jawabannya karena total luas tanah seluruh anak adalah $1200 \mathrm{~m}^{2}$ dan total persentase luas tanah seluruh anak adalah $100 \%$

Skema learning trajectory S2 dalam memecahkan M1 disajikan sebagai berikut.

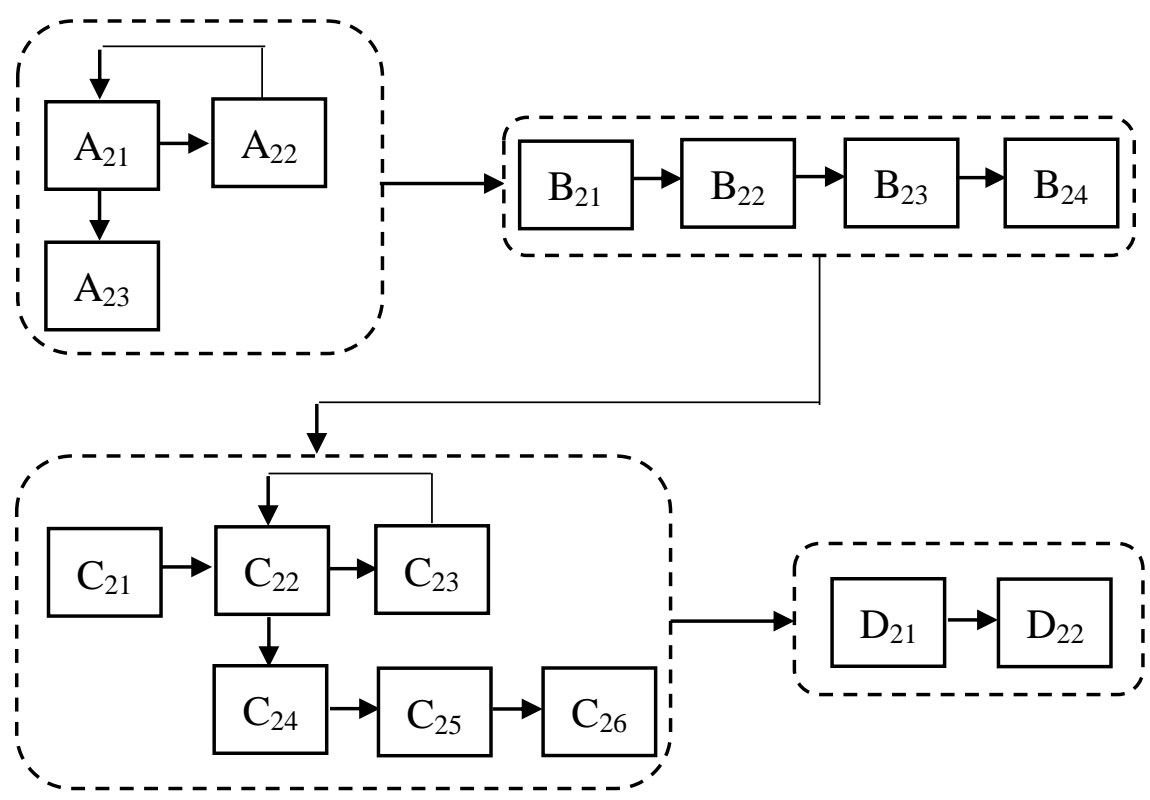

Gambar 6. Skema Learning Trajectory S2 berikut.

Arti kode yang digunakan pada skema tersebut dirincikan dalam Tabel 10. sebagai

Tabel 10. Arti Kode Skema Learning Trajectory S2

\begin{tabular}{|c|c|}
\hline Kode & Arti Kode \\
\hline $\mathrm{A}_{21}$ & Mengidentifikasi satu per satu informasi yang diketahui \\
\hline $\mathrm{A}_{22}$ & Mengidentifikasi hal yang ditanyakan \\
\hline $\mathrm{A}_{23}$ & Mengidentifikasi kelengkapan informasi yang dibutuhkan untuk menyelesaikan M1 \\
\hline $\mathrm{B}_{21}$ & $\begin{array}{l}\text { Merencanakan penggunaan pengubahan bentuk pecahan menjadi persen untuk memperoleh } \\
\text { kavelingan milik Hendra, Ahsan, dan Rian }\end{array}$ \\
\hline $\mathrm{B}_{22}$ & $\begin{array}{l}\text { Merencanakan penggunaan operasi perkalian pecahan dengan luas keseluruhan tanah untuk } \\
\text { memperoleh luas tanah milik mereka masing-masing }\end{array}$ \\
\hline $\mathrm{B}_{23}$ & $\begin{array}{l}\text { Merencanakan penggunaan operasi hitung seperti pembagian, pengurangan, dan penjumlahan } \\
\text { bilangan bulat untuk memperoleh luas tanah milik mereka masing-masing setelah Hendra } \\
\text { memberikan setengah dari luas kavelingan miliknya kepada Ahsan dan Rian }\end{array}$ \\
\hline $\mathrm{B}_{24}$ & $\begin{array}{l}\text { Merencanakan penggunaan pengubahan bilangan bulat menjadi persen untuk memperoleh } \\
\text { persentase luas tanah milik mereka masing-masing }\end{array}$ \\
\hline $\mathrm{C}_{21}$ & $\begin{array}{l}\text { Mengubah bentuk pecahan menjadi persen untuk memperoleh kavelingan milik Hendra, Ahsan, } \\
\text { dan Rian }\end{array}$ \\
\hline $\mathrm{C}_{22}$ & $\begin{array}{l}\text { Melakukan perkalian pecahan dengan luas keseluruhan tanah untuk memperoleh luas } \\
\text { sebenarnya masing-masing kavelingan }\end{array}$ \\
\hline $\mathrm{C}_{23}$ & $\begin{array}{l}\text { Melakukan pembagian bilangan bulat untuk memperoleh luas tanah yang ingin diberikan } \\
\text { Hendra kepada Ahsan dan Rian }\end{array}$ \\
\hline $\mathrm{C}_{24}$ & $\begin{array}{l}\text { Melakukan pengurangan bilangan bulat untuk memperoleh luas tanah yang masih dimiliki } \\
\text { Hendra }\end{array}$ \\
\hline $\mathrm{C}_{25}$ & $\begin{array}{l}\text { Melakukan penjumlahan bilangan bulat untuk memperoleh luas tanah yang dimiliki Ahsan dan } \\
\text { Rian setelah ditambah dengan pemberian dari Hendra }\end{array}$ \\
\hline
\end{tabular}


$\mathrm{C}_{26}$ Mengubah bilangan bulat menjadi persen untuk memperoleh persentase luas tanah milik mereka masing-masing

$\mathrm{D}_{21} \quad$ Mengecek perhitungan yang telah dilakukan di kertas coret-coretan dan

$\mathrm{D}_{22}$ Meyakini kebenaran jawabannya karena perhitungan yang dilakukan telah benar

\section{KESIMPULAN}

Pada tahap memahami masalah, S1 dan S2 mula-mula mengidentifikasi satu per satu informasi yang diketahui, kemudian mengidentifikasi hal yang ditanyakan, hingga akhirnya menyatakan bahwa informasi yang tersedia telah cukup agar masalah dapat diselesaikan. Pada tahap menyusun rencana, S1 dan S2 memanfaatkan seluruh informasi yang tersedia, tetapi perencanaan S1 lebih ringkas dibandingkan perencanaan S2 yang bersifat tumpang tindih. Pada tahap melaksanakan rencana, S1 dan S2 menyelesaiakan masalah sesuai dengan perencanaan yang telah disusun, tetapi penyelesaian S1 lebih ringkas dibandingkan S2. Pada tahap memeriksa kembali, S1 menggunakan alternatif pemeriksaan yang berbeda dari penyelesaian yang telah dilakukannya, sedangkan S2 menelusuri kembali perhitungan yang telah dilakukannya. Perbedaan keduanya di setiap tahapan pemecahan masalah menunjukkan bahwa learning trajectory siswa perempuan yang berkemampuan matematika tinggi lebih pendek dari siswa perempuan yang berkemampuan matematika rendah.

\section{SARAN}

Berdasarkan hasil deskripsi learning trajectory siswa dalam memecahkan masalah pecahan, maka peneliti menyarankan perlu adanya penelitian lebih lanjut tentang learning trajectory siswa serta faktor apa saja yang mempengaruhinya, sehingga faktor yang menyebabkan panjangnya aktivitas berpikir siswa tersebut dapat diminimalisir oleh guru melalui pembelajaran yang terencana. Selain itu, guru diharapkan dapat mempertimbangkan untuk merencanakan pembelajaran yang memperhatikan learning trajectory siswa. Pengetahuan tentang learning trajectory siswa akan mendorong guru untuk memfasilitasi siswa agar mampu melihat keterkaitan informasi yang dibutuhkan serta menerapkan konsep yang tepat untuk menyelesaikan masalah dengan cara yang sesederhana mungkin agar penyelesaian masalah dapat berlangsung dengan efektif.

\section{DAFTAR PUSTAKA}

Anwar dan Rofiki, I. (2018). Investigating students' learning trajectory: A case on triangle. Journal of Physics: Conference Series, 1088 (10): 1-6.

Baroody, A. J. \& Coslick, R. T. (1998). Fostering children mathematical power: An investigate approach to $k-8$ mathematics instruction. New Jersey: Lawrence Erlbaum Associates, Inc.

Clements, D. H. dan Sarama, J. (2004). Learning trajectories in mathematics education. Mathematical Thinking and Learning, 6 (2): 81-89.

Fennel, F. (2007). Fractions are Foundational. National Council of Teachers of Mathematics, (Online), (https://www.nctm.org/News-and-Calendar/Messages-fromthe-President/Archive/Skip-Fennell/Fractions-Are-Foundational/), diakses 17 November 2019. 
Moleong, L. J. (2018). Metodologi penelitian kualitatif. Bandung: Remaja Rosdakarya.

Nurdin. (2011). Trajektori dalam pembelajaran matematika. Education, 1 (1): 1-7.

Polya, G. (1973). How to solve it: A new aspect of mathematical method. New Jersey: Princeton University Press.

Rizal, M. (2011). Proses berpikir siswa sekolah dasar melakukan estimasi dalam pemecahan masalah berhitung ditinjau dari kemampuan matematika dan jenis kelamin. Disertasi, Program Studi Pendidikan Matematika, Universitas Negeri Surabaya. Surabaya. Tidak Dipublikasikan.

Syamsudin, Awuy, E., dan Sukayasa. (2019). Profil pemahaman konsep operasi pecahan bentuk aljabar siswa Kelas VIII MTs Bina Potensi Sis Aljufri Tatura Palu. Aksioma: Jurnal Pendidikan Matematika, 8 (1): 29-43. 